$\begin{array}{ll} & \text { Etnográfica } \\ \text { etnográfica } & \text { Revista do Centro em Rede de Investigação em }\end{array}$

Antropologia

vol. 15 (3) | 2011

Vol. 15 (3)

\title{
Stefania Capone, Searching for Africa in Brazil: Power and Tradition in Candomblé
}

\section{Diana Espírito Santo}

\section{OpenEdition \\ Journals}

\section{Edição electrónica}

URL: https://journals.openedition.org/etnografica/1099

DOI: 10.4000/etnografica.1099

ISSN: 2182-2891

\section{Editora}

Centro em Rede de Investigação em Antropologia

\section{Edição impressa}

Data de publição: 1 outubro 2011

Paginação: 614-616

ISSN: 0873-6561

\section{Refêrencia eletrónica}

Diana Espírito Santo, «Stefania Capone, Searching for Africa in Brazil: Power and Tradition in Candomblé», Etnográfica [Online], vol. 15 (3) | 2011, posto online no dia 23 outubro 2011, consultado o 12 fevereiro 2022. URL: http://journals.openedition.org/etnografica/1099; DOI: https://doi.org/10.4000/ etnografica.1099

Etnográfica is licensed under a Creative Commons Attribution-NonCommercial 4.0 International License. 
o deslocamento de Konis para a região Haksolok, depois chamada de "Região 4", em 1986, Mattoso relata as dificuldades na construção de relações de solidariedade e apoio junto da população em razão da diversidade linguística existente (p. 125).

$\mathrm{O}$ autor arrisca-se ainda em uma narrativa sedutora, ao sugerir que o engajamento de grande parte da população timorense no apoio ou ação direta na resistência foi produzido em razão de os ocupantes terem humilhado os leste-timorenses, indo de encontro ao seu sentido de dignidade e respeito. No entanto, não há fatos históricos sustentando tal interpretação. Por sedutora que seja a sugestão - figurando quase que como uma metanarrativa -, ela esbarra primeiramente na extensão do valor da defesa da dignidade a todos que habitam as fronteiras sociopolíticas do que hoje chamamos de Timor-Leste. Mas como explicar os esforços que foram necessários para conquistar o apoio da população por parte das frentes armada e clandestina e, apesar disso, o apoio à ocupação de muitos leste-timorenses? Talvez a questão seja justamente a validade analítica de categorias

Stefania Capone

SEARCHING FOR AFRICA IN BRAZIL: POWER AND TRADITION IN CANDOMBLÉ

Durham e Londres, Duke University Press, 2010, xiv +316 páginas, trad. Lucy Lyall Grant.

Esta convincente tradução do livro La quête de l'Afrique dans le candomblé: Pouvoir et tradition au Brésil (1999) finalmente disponibiliza a antropólogos não francófonos a como "timorenses" ou "leste-timorenses". De um ponto de vista antropológico, elas nos dizem muito pouco. Em minhas investidas de pesquisa entre a elite política moderna leste-timorense, a ideia de dignidade aparece como importante mobilizador político. Seu sentido, contudo, é inverso àquele que lhe atribuímos no senso comum ocidental. Ele é muito mais próximo daquilo que nossa episteme qualifica como honra. Em tal universo empírico, dignidade significa ser reconhecido em uma certa posição hierárquica que prescreve deferência e obediência. Àqueles que a detêm cabe um decoro particular, que proíbe a ofensa ou a desconsideração aos outros em público.

Por fim, a obra de Mattoso, edificada com a colaboração de José Sequeira (Somotxo) e Florbela Marante, é também um convite a explorar mais a fundo a história da resistência - tarefa urgente, dado o desaparecimento progressivo de seus heróis e protagonistas anônimos.

\section{Kelly Silva}

Departamento de Antropologia

da Universidade de Brasília

trabalharem na área das religiões "afro" no Brasil a obra principal de Capone, cujos valor antropológico e riqueza etnográfica são incontestáveis. Capone é veterana neste contexto etnográfico, começando o seu percurso de investigação no final dos anos 80 no Rio de Janeiro, nomeadamente a partir do seu estudo de casas de Candomblé da nação Efon. Fascinada com a continuada predominância de certos modelos de pureza religiosa, como os da chamada tradição Nagô, associados às vertentes Ioruba no Candomblé, Capone dedica-se neste 
trabalho a demonstrar o quão imbricadas estão as trajetórias dos antropólogos e líderes e intelectuais religiosos na fabricação do mito da ortodoxia religiosa. Neste mito, certas modalidades religiosas são vistas como o estandarte da tradição "africana" e outras como a sua manifestação degenerada e infetada. Visto através da lente do seu desenrolar histórico, entre outros na escrita de Nina Rodrigues e até de Roger Bastide, em jogo na propagação deste mito estaria a oposição entre a religião e a magia, entre força e fraqueza cultural, e um conceito de superioridade racial dentro do complexo de heranças africanas na definição destas. Capone mostra-nos com impressionante detalhe a natureza complexa mas construída de polaridades como as estabelecidas entre a "macumba" (tida tipicamente como um conjunto de práticas urbanas largamente desprovidas de coerência religiosa), e outras tradições no Candomblé como o "Angola" e os Candomblés da Baía, a sua antítese, nos quais alguns dos antropólogos mais influentes ingressariam, por vezes até iniciando-se, tornando-os modelos analíticos além de etnográficos.

A contribuição de Capone neste livro reside não apenas na sua capacidade de sintetizar as correntes principais do que é sem dúvida um campo extenso de informação e contradição, principalmente para quem o leia sem qualquer conhecimento prévio. O seu sucesso apoia-se também na sua exploração magistral da ideia de que a religião afro-brasileira é de facto constituída por uma série de articulações através das quais modalidades como a Umbanda e o Candomblé, tradicionalmente concebidas separadamente, se encontram num só "contínuo", no qual um sem-número de práticas e narrativas, inclusivas ou exclusivas, são possíveis e até necessárias. Chamo a atenção para a originalidade da abordagem com respeito à sua desconstrução da relação cosmológica e ritual (além de sociológica) entre estas duas vertentes da religião e a força das suas estratégias de delimitação, talhada em particular através da análise do orixá Exu (mensageiro dos deuses, dono dos caminhos e do movimento), nas suas variadas manifestações ontológicas e pessoais.

Capone divide o livro em três partes. Na primeira, "The metamorphoses of Exu”, a autora guia-nos pelas origens da figura de Exu, o inversor por excelência da ordem social, descrevendo os seus mitos e associações nos vários ramos da religião e a sua função fundamental nos terreiros contemporâneos, além da sensível natureza da sua conceptualização. No Xangô do Recife, por exemplo, distingue-se entre Exus "batizados" (Exu como divinidade) e "pagãos" (Exu como entidade). Esta será uma classificação explorada pela autora através das categorias de Exu-egun e Exu-orixá e suas refrações. Para contextualizar esta dualidade, Capone introduz-nos à Umbanda da década de 20, considerada uma tentativa de "desafricanização". A autora realça, porém, a existência de um vasto cosmos de praticantes cujas entidades - o "povo da rua" - não se contêm dentro dos parâmetros visados pelos fundadores: além dos espíritos dos escravos, dos pretos-velhos, das crianças (êres), e de Exus batizados, que teriam uma ligação direta com os orixás do Candomblé, os múltiplos Exus pagãos, como o conhecido Zé Pilintra, e as pombagiras sedutoras e rebeldes, como Maria Padilha, incarnariam algumas das imagens mais relevantes do imaginário popular religioso. A Quimbanda, o lado escuro da Umbanda, emergiria como um padrão de acusação entre médiuns nos discursos morais, inimiga, porém necessária e complementar, da formação da Umbanda mais difundida.

Nos capítulos da segunda parte, "Ritual practice", Capone salienta o caráter fluido e combinatório do campo religioso afro-brasileiro, a existência de entidades "traçadas" e "cruzadas", tanto dentro do Candomblé 
como da Umbanda, assinalando a existência de formas religiosas tais como o Omolocô (que se posicionaria entre as duas) como evidência de um contínuo orgânico de práticas, indivisível. Capone mostra que a construção do Candomblé como religião universal estará predicada na oposição entre cultos puros e degenerados, traçando com fluência o contexto sociopolítico e racial e a sua cristalização no Rio de Janeiro e além. Capone analisa os mecanismos pelos quais os Candomblés da Baía se tornariam símbolos culturais na década de 1970, influenciando movimentos literários, artísticos e musicais. A visibilidade de alguns dos líderes destes templos ajudaria a que o estigma do Candomblé se esvanecesse, mas também a que o culto se identificasse com estes mesmos templos. Capone afirma que, para o médium umbandista, a transição para o Candomblé começaria a implicar prestígio e, para além, uma via pela qual buscar e justificar origens, raízes e cientificidade. Embora mencione brevemente outra opção - a trajetória "reamericanizadora" da Umbanda (que se vê hoje em casas que postulam a sua ancestralidade indígena), Capone sublinha a natureza reafricanizadora desta passagem, analisando a reorganização ontológica e ritual necessária por parte de ambos, o médium e o seu novo pai-de-santo. A questão do espaço tornar-se-ia crucial para a resolução das tensões latentes entre os iniciados de uma e de outra. Capone demonstra aqui o potencial subversivo e contestador dos Exus da Umbanda, através de uma série de casos de estudo que apontam para a centralidade de questões de poder, género e individualidade no desenvolvimento religioso.

Na terceira parte - intitulada "The construction of tradition" -, Capone efetua uma leitura crítica da figura de Exu na antropologia e na sociedade brasileira mais amplamente, na qual tece noções de raça, ciência e cidadania através do prisma da religião "afro" e associadas representações. Salienta-se o papel da negação do culto de Exu na construção da diferença entre a cultura Bantu e Nagô, e como os antropólogos do Candomblé do século XX se tornariam autores da autenticidade. Capone descreve como paradigmático o movimento de retorno a África na religião brasileira, marcado pelo início de um trânsito religioso e intelectual entre o Brasil e África, no qual também participaria Pierre Verger, antropólogo e figura emblemática. O resultado: um acréscimo de autoridade, frequentemente favorecendo certas redes religiosas. Mas, como diz Capone, "the founding myth in Candomblé in Brazil seems to be built upon a lack of full knowledge and the perpetual search for forgotten secrets" (p. 214). Como David Brown ilustra em relação à Santería cubana (em Santeria Enthroned, The University of Chicago Press, 2003), Capone mostra de maneira formidável os acasos, as personagens e as decisões que possibilitaram a invenção da tradição no Brasil no século XX. Capone também se dedica a mostrar alguns dos efeitos deste movimento de reafricanização, entre os quais está a redefinição deste mesmo processo como algo que paradoxalmente já não implicará a África necessariamente. Como diria Stephan Palmié (2008, Africa of the Americas, Leiden, Brill Academic Publishers), nem a África é um dado ontológico.

\section{Diana Espírito Santo}

Instituto de Ciências Sociais da Universidade de Lisboa 